\title{
Phenol Adsorption from Simulated Wastewater on Rice Husk Activated Carbon and Granular Activated Carbon
}

\author{
Riham Ali Hazzaa \\ Petrochemical Department, Faculty of Engineering, Pharos University in Alexandria, Egypt
}

\begin{abstract}
Background: Phenol has been classified as hazardous pollutant and its presence in natural water is considered as a serious threat to human health and overall water quality. The major source of phenol pollution in the aquatic environment is wastewater from petroleum and petrochemical industries. Objective: This study aims to investigate the adsorption efficiency of granular activated carbon (GAC) and activated carbon prepared from rice husk (RHAC), a lowcost agricultural by product, in removing phenols from simulated wastewater. Methods: Batch adsorption studies were conducted to study the effect of various parameters such as initial concentration, agitation time, adsorbent dose and solution $\mathrm{pH}$ on phenol removal. Equilibrium data were analyzed by the Langmuir, Freundlich, Temkin and Hurkin-Jura. The adsorption kinetics were studied using the pseudo-first-order and second-order kinetics models. The mechanism of the adsorption process was determined from the intraparticle diffusion model. Results: The efficiency of GAC and RHAC on removal of phenol was $95 \%$ and $90 \%$ respectively at an agitation time of $6 \mathrm{hr}$, a pH 6,150 rpm, an adsorbent dose of $5 \mathrm{~g} / \mathrm{L}$, initial phenol concentration of $50 \mathrm{mg} / \mathrm{L}$ and a temperature of $20^{\circ} \mathrm{C}$. Acidic $\mathrm{pH}$ was more favorable for the removal of phenol. Increasing initial concentration of phenol decreases the percentage removal. The adsorption isotherm models fitted the data in the order: Freundlich > Langmuir > Tempkin isotherms. The pseudo-second-order kinetic model best described the adsorption process Conclusion: The results showed that the prepared activated carbon was an effective adsorbent for removal of phenol as a low-cost and an alternative adsorbent.
\end{abstract}

Available on line at:

https://www.ebscohost.com/academic/arabworld-research-source

$¥$ Correspondence:

Email: Riham17@yahoo.com

Suggested Citation: Hazzaa RA. Phenol adsorption from simulated wastewater by rice husk activated carbon and granular activated carbon. Bull High Inst Public Health. 2014; 44(2): 77-87.

Keywords: Adsorption, phenol, Granular activated carbon, Rice husk, Wastewater

\section{INTRODUCTION}

$\mathrm{P}$ henols are generally considered to be one of the toxic pollutants discharged into surface even at low concentrations. The major source of phenol pollution in the rivers are effluent wastewaters from pharmaceuticals, rubber, dye, surfactants, fertilizers, explosives, paints, petroleum, and petrochemical industries. ${ }^{(1)}$ Their public health impacts due to exposure to low levels in water are liver damage, mouth ulcers, and haemolytic anaemia. Phenol affects kidneys, lungs, and vascular system. ${ }^{(2)}$ The US Environmental Protection Agency (EPA) regulations call for lowering phenol content in the wastewater to less than $1 \mathrm{mg} / \mathrm{L} .{ }^{(3)}$ World Health Organization (WHO) recommends the permissible phenolic concentration of $0.001 \mathrm{mg} / \mathrm{l}$ in potable water. ${ }^{(4)}$
Several physico-chemical treatments have been proposed for efficient phenol removal, such as membrane-filtration processes (nanofiltration, reverse osmosis, electrodialysis, etc.), adsorption ${ }^{(5)}$, electrochemical oxidation, wet oxidation, heterogeneous photocatalysis ${ }^{(6)}$ and biological treatments. ${ }^{(7)}$

Adsorption process is efficient for the removal of organic matter from waste effluents. Adsorption has been found to be superior compared to other techniques for water reuse in terms of flexibility and simplicity of design, ease of operation and insensitivity to toxic pollutants. Adsorption also does not result in the formation of harmful substances. ${ }^{(8)}$

Activated carbons are the most widely used adsorbents due to their excellent adsorption abilities for organic pollutants. The high adsorption capacities 
of activated carbons are usually related to their highsurface-area, pore volume, and porosity. ${ }^{(9)}$ In addition, the adsorption capabilities of activated carbons strongly depend on the activation method and the nature of source materials. Many researchers have shown that activated carbon is an effective adsorbent for organic compounds removal, especially for phenolic compounds. ${ }^{(10)}$ However, its high initial cost and difficulty in regeneration make it less economically viable as an adsorbent and limit its use. Many researchers examined the feasibility of using cheaper raw materials of agricultural waste origin to prepare activated carbon ${ }^{(11)}$ such as corn $\operatorname{cob}^{(12)}$, sun flower seed hull ${ }^{(13)}$, coconut husk $^{(14)}$, soybean straw ${ }^{(15)}$, sugarcane bagasse ${ }^{(16)}$, rice and husk. $^{(17,18)}$

Rice husk is an agricultural waste and a by-product of the rice milling industry about more than 100 million tonnes, $96 \%$ of which is generated in the developing countries. The utilization of this source of agricultural waste would solve both a disposal problem as well as access to a cheaper material for adsorption in water pollutants control system ${ }^{(19-20)}$

The present study aimed to compare the adsorption of phenol by active carbon prepared from rice husk (RHAC) and commercial granular activated carbon (GAC). The equilibrium and kinetic data of the adsorption were studied.

\section{METHODS}

Study setting: The present study was an experimental study performed in the laboratory of Chemical Engineering Department, Faculty of Engineering, Alexandria University and Pharos University, Alexandria, Egypt.

Study design: Batch adsorption experimental study was employed for the removal of phenol onto activated carbon prepared from rice husk and granular activated carbon.

Analyses: Stock solution of phenol $(1000 \mathrm{mg} / \mathrm{L})$ was prepared using double-distilled water. All solutions were prepared fresh whenever required. Phenol was analyzed by UV-vis spectrophotometer (UV Shimadzu, Japan) at a wavelength of $269 \mathrm{~nm}$. The $\mathrm{pH}$ of the solution was adjusted using $0.1 \mathrm{M}$ hydrochloric acid and $0.1 \mathrm{M}$ sodium hydroxide. All chemicals used were of analytical reagent grade and purchased from Merck.

Materials: Two different types of activated carbon were used in this study: Commercial granular activated carbon (GAC) and activated carbon prepared from Rice husks (RHAC). GAC had an average particle size of $0.8 \mathrm{~mm}$ to 1 $\mathrm{mm}$. The moisture content was $4.136 \%$ and the iodine value was $550 \mathrm{mg} / \mathrm{g}$. Bulk density of GAC was $590.13 \mathrm{~kg} /$ L. GAC was dried for $2 \mathrm{~h}$ in an oven at $110{ }^{\circ} \mathrm{C}$, then packed and stored in stoppered bottles for use.

Rice husks were obtained from local Rice Mill in Egypt. Rice husks were washed thoroughly with double distilled water to remove any dirt, then oven- dried at about $110{ }^{\circ} \mathrm{C}$ for $6 \mathrm{~h}$. The dried rice husks were subjected to thermal carbonization in a muffle furnace at $800{ }^{\circ} \mathrm{C}$ for $1 \mathrm{~h}$. The samples obtained, were ground in a ball mill and sieved to obtain the particles size of $0.5 \mathrm{~mm}$ to $0.8 \mathrm{~mm}$. The product was adequately cooled and stored in a vacuum desiccator until required. The moisture content of RHAC was $6.335 \%$ and the iodine value was $320 \mathrm{mg} / \mathrm{g}$. Bulk density of RHAC was $480 \mathrm{~kg} / \mathrm{L}$.

\section{Experimental Procedure}

Batch experiments: Batch experiments were carried out to study the effect of various operating parameters on the adsorption process. For each experimental run, a known concentration of phenol of $100 \mathrm{ml}$ volume was taken in a glass stoppered conical flask $(250 \mathrm{~mL})$ and shaken at the rate of $150 \mathrm{rpm}$ with a known amount of adsorbent using temperature-controlled horizontal shaker kept at $20^{\circ} \mathrm{C}$.

Adsorption experiments: Batch adsorption experiments were carried out in a series of stoppered conical flasks $(250 \mathrm{ml})$. Weighted amounts of GAC and RHAC were introduced into the bottles containing various concentrations of phenol $(50-250 \mathrm{mg} / \mathrm{l})$. The total volume of the solution was $100 \mathrm{ml}$. The conical flasks were agitated in a temperature-controlled horizontal shaker at a constant speed of $150 \mathrm{rpm}$ at $20^{\circ} \mathrm{C}$ to reach the equilibrium time .The effects of contact time, initial concentration of phenol $(50-250 \mathrm{mg} / \mathrm{l})$, solution $\mathrm{pH}(2-10)$ and adsorbent doses $(2-6 \mathrm{~g} / \mathrm{L})$ were studied. The $\mathrm{pH}$ measurements were made using a $\mathrm{pH}$ meter

The percentage removal of phenol from solution was calculated by the following equation ${ }^{(21)}$ :

$$
\text { Removal \% }=\frac{\left(C_{i}-C_{t}\right)}{C_{i}} \times 100
$$

Kinetics of adsorption was determined by analyzing adsorptive uptake of the phenol from the solution at different time intervals and calculated from the following equation ${ }^{(21)}$ :

$\mathrm{q}_{\mathrm{t}}=\frac{\left(\mathrm{C}_{\mathrm{i}}-\mathrm{C}_{\mathrm{t}}\right)}{\mathrm{m}} \times \mathrm{V}$

Batch tests were carried out to compare the adsorptive capacity of GAC and RHAC. Equilibrium adsorption capacity was calculated from the following relationship ${ }^{(21)}$ $\mathrm{q}_{\mathrm{e}}=\frac{\left(\mathrm{C}_{\mathrm{i}}-\mathrm{C}_{\mathrm{e}}\right)}{\mathrm{m}} \times \mathrm{V}$

Where, $C_{i}$ is the initial phenol concentration, $C_{t}$ is the phenol concentration at time $(t), C_{e}$ is the phenol concentration at equilibrium time, $\mathrm{V}(\mathrm{L})$ is the volume of solution and $\mathrm{m}(\mathrm{g})$ is the weight of adsorbent.

\section{Statistical Analysis}

Each experiment was carried out in duplicate and the average of two values was used in the calculations. The maximum difference between the two values was less than $3 \%$ of the mean.

Chi-square statistic test and the average percentage errors were used. ${ }^{(22)}$ The average percentage errors indicate the fit between the experimental and calculated values of adsorption capacity used for plotting isotherm 
curves. The average percentage errors (APE) were calculated according to the following equation: ${ }^{(22)}$

$A P E(\%)=\frac{100}{\mathrm{~N}} \times \frac{\left.\sum_{\mathrm{i}}^{\mathrm{N}} \mid \text { (qe experimental }- \text { qe calculated }\right) \mid}{\text { qe experimental }}(4)$

The Chi-square test statistic is basically the sum of the squares of the differences between the experimental data and data obtained by calculation from models, with each squared difference divided by the corresponding data obtained by calculation from models: ${ }^{(22)}$

$\boldsymbol{X}^{\mathbf{2}}=\sum_{i}^{N} \frac{(\text { qe experimental }- \text { qe calculated })^{2}}{\text { qe calculated }}$

Where qe, calculated is the calculated adsorbate concentration at equilibrium $(\mathrm{mg} / \mathrm{g})$, qe, experimental is the measured adsorbate concentration at equilibrium $(\mathrm{mg} / \mathrm{g}), \mathrm{N}$ is the number of data points.

\section{RESULTS}

Effect of contact time: Figure 1 shows the effect of contact time on the removal percentage of phenol by GAC and RHAC. The removal of phenol increased with increase in contact time for both GAC and RHAC. The adsorption was rapid during the initial $3 \mathrm{hr}$ and then reached equilibrium at $6 \mathrm{hr}$. No significant change in phenol removal was observed after $4 \mathrm{hrs}$. The removal of phenol by RHAC was slightly less than that by GAC. The removal percentage of phenol onto GAC and RHAC was $90 \%$ and $83 \%$ respectively.

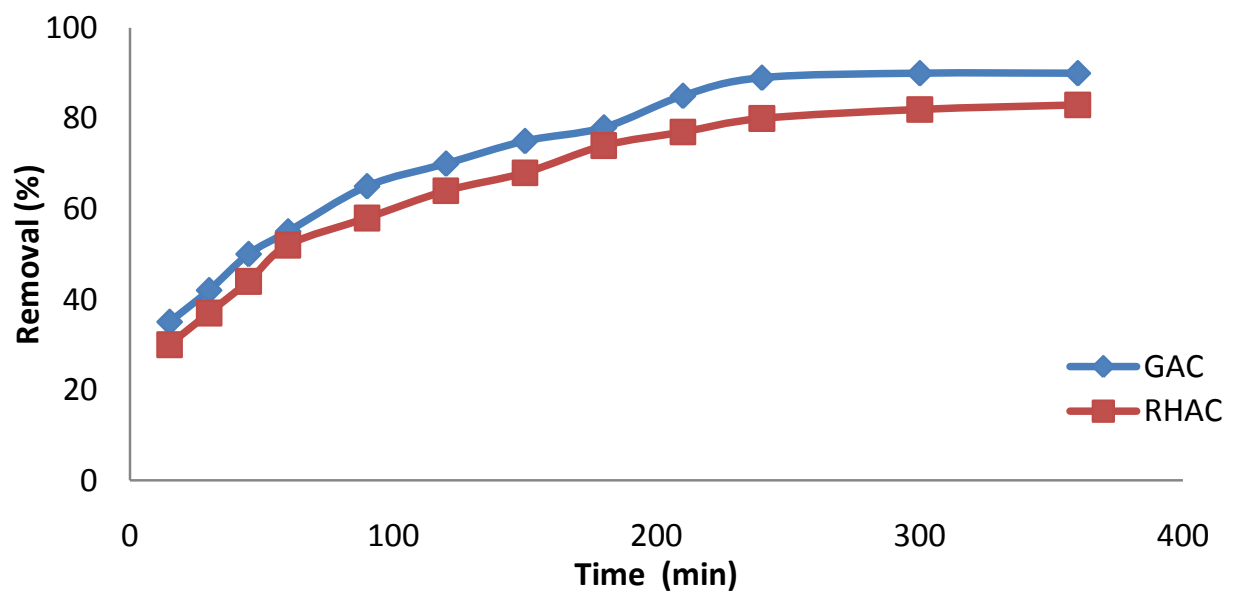

Figure1: Effect of contact time on the adsorption of phenol on RHAC and GAC (pH 6, temperature $20{ }^{\circ} \mathrm{C}$, adsorbent dose $5 \mathrm{~g} / \mathrm{L}$, phenol concentration $100 \mathrm{mg} / \mathrm{L}$ )

Effect of solution pH: The $\mathrm{pH}$ of the sorption medium is one of the most significant parameters in the adsorption process. The $\mathrm{pH}$ primarily affects the degree of ionization of the phenolic adsorbate and the surface properties of the adsorbent, i.e. the functional groups on the carbon surface. Figure 2 illustrates the effect of solution $\mathrm{pH}$ on the removal percentage of phenol in the $\mathrm{pH}$ range of 2-10. The results show that the highest phenol removal was achieved at $\mathrm{pH} 6$, with a phenol removal of $92 \%$ and $80 \%$ for GAC and RHAC, respectively at phenol initial concentration of $100 \mathrm{mg} / \mathrm{l}$.

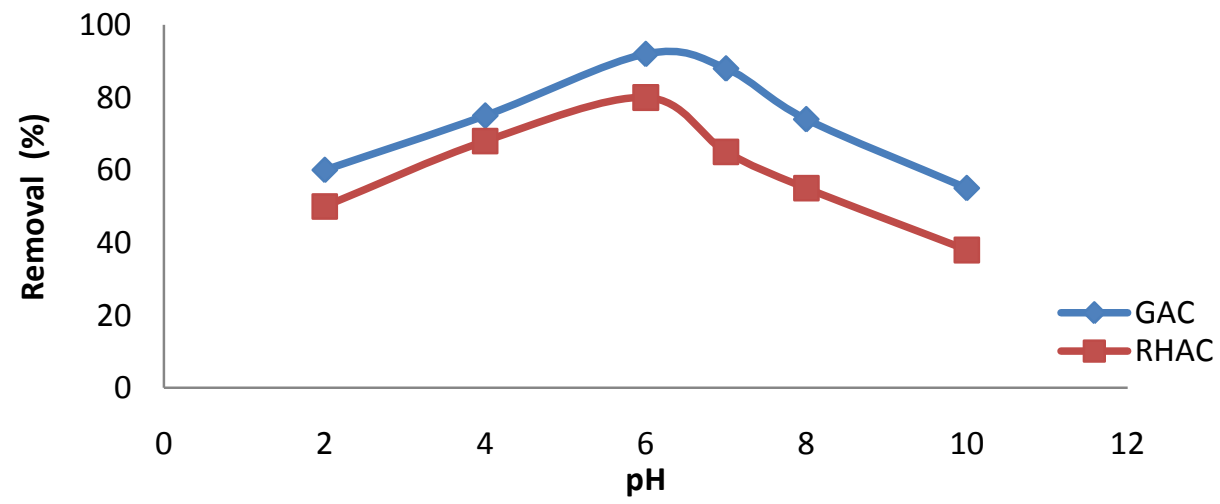

Figure 2: Effect of solution pH on the removal of phenol by RHAC and GAC (phenol concentration 100 $\mathrm{mg} / \mathrm{L}$, temperature $20^{\circ} \mathrm{C}$, adsorbent dose $5 \mathrm{~g} / \mathrm{L}$ contact time $6 \mathrm{~h}$ ) 
Effect of adsorbent dose: Figure 3 shows the effect of adsorbent dose on removal percentage of phenol. Amount of adsorbent carried out was 2-6 g/L at $6 \mathrm{hr}$ of agitation time using $100 \mathrm{ml}$ of phenol concentration at $\mathrm{pH} 6$ and $150 \mathrm{rpm}$ shaking speed and at a temperature of $20{ }^{\circ} \mathrm{C}$. Figure 3 illustrates that the percentage removal of phenol increases by increasing the amount of the adsorbent for both GAC and RHAC. Removal percentage of phenol onto GAC were $78 \%$ and $95 \%$ for dosage of $2 \mathrm{~g} / \mathrm{L}$ and $6 \mathrm{~g} / \mathrm{L}$, respectively, while the removal percentages of phenol onto RHAC were $67 \%$ and $82 \%$ for dosage of $2 \mathrm{~g} / \mathrm{L}$ and $6 \mathrm{~g} / \mathrm{L}$, respectively .

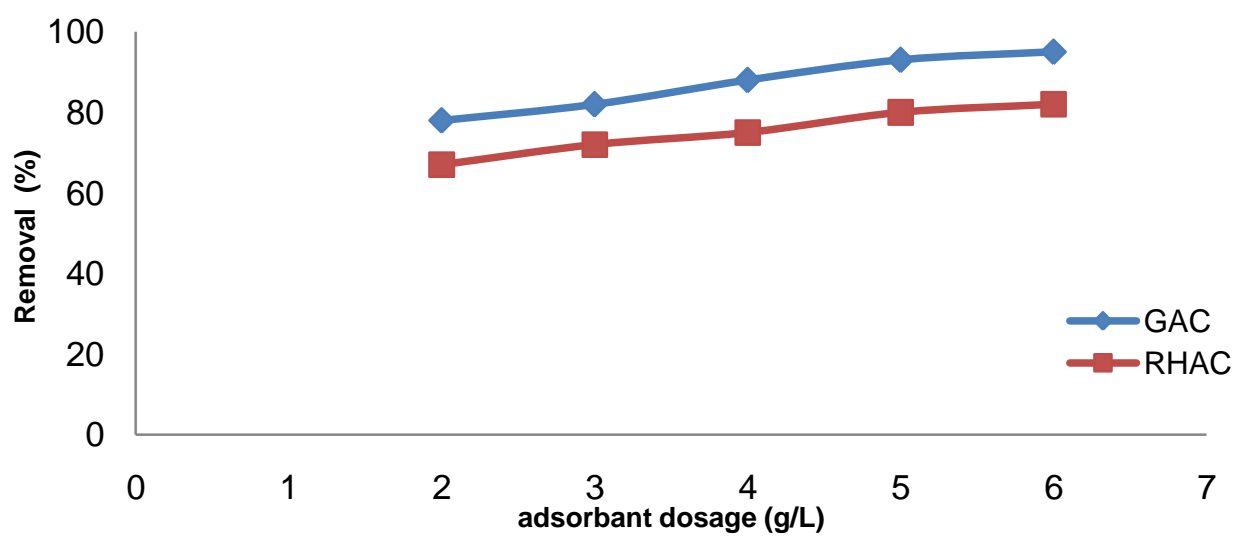

Figure 3: Effect of adsorbent dose on the removal of phenol by RHAC and GAC (pH 6, temperature $20{ }^{\circ} \mathrm{C}$, phenol concentration $100 \mathrm{mg} / \mathrm{L}$ )

Effect of initial concentration: Figure 4 presents the effect of initial concentration of phenol on the removal percentage of phenol onto GAC and RHAC within a range of $50-250 \mathrm{mg} / \mathrm{L}$. The results reveal that the removal percentage decreases as the initial phenol concentration is increased. The removal percentage of phenol onto GAC and RHAC was 95\% and 90\%, respectively at an initial phenol concentration of 50 $\mathrm{mg} / \mathrm{L}$, while a percentage removal of phenol of $75 \%$ and $65 \%$ was determined onto GAC and RHAC respectively at an initial phenol concentration of 250 $\mathrm{mg} / \mathrm{L}$.

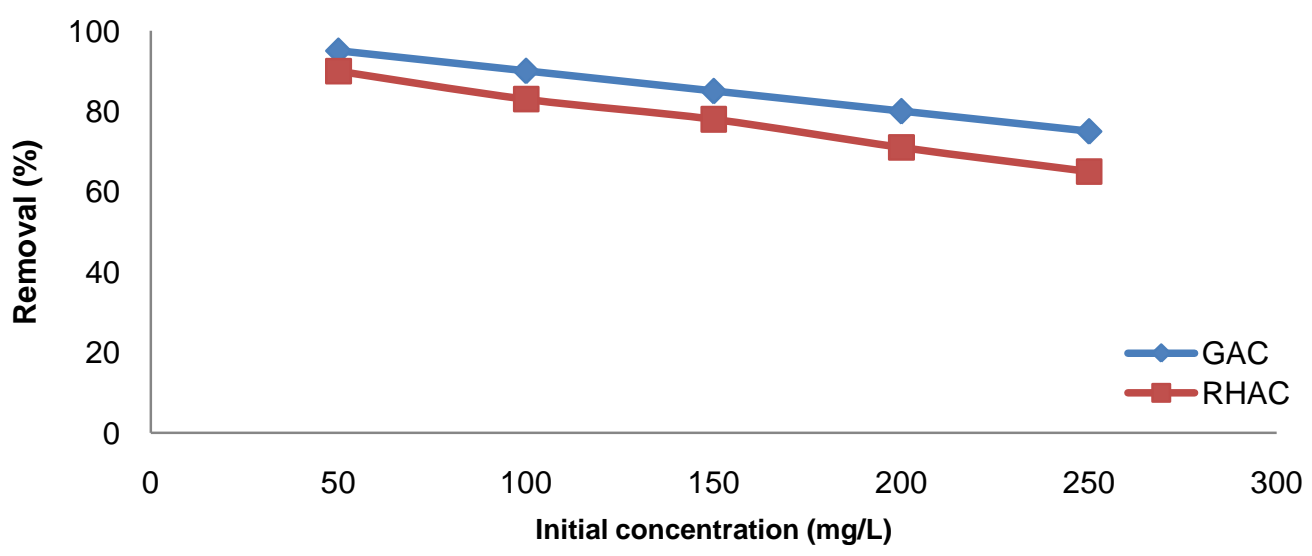

Figure 4: Effect of initial concentration on the removal of phenol by RHAC and GAC (pH 6, temperature 20 ${ }^{\circ} \mathrm{C}$, adsorbent dose $5 \mathrm{~g} / \mathrm{L}$, contact time 6h)

Adsorption isotherms: Adsorption isotherms indicate how the adsorbate is distributed between the liquid phase and the solid phase when the adsorption process reaches equilibrium state. In this study, Langmuir,
Freundlich, Temkin and Hurkins -Jura adsorption isotherms were applied to the equilibrium data of adsorption of phenol onto both GAC and RHAC. The Langmuir equation ${ }^{(23)}$ is valid for monolayer sorption 
on a surface with a finite number of identical sites and is expressed as:

$$
\frac{C_{e}}{q_{e}}=\frac{1}{Q_{m} K_{L}}+\frac{1}{Q_{m}} C_{e}
$$

Where $\mathrm{Q}_{\mathrm{m}}\left(\mathrm{mg} \mathrm{g}^{-1}\right)$ is the monolayer adsorption capacity, and $\mathrm{K}_{\mathrm{L}}\left(\mathrm{L} \mathrm{mg}^{-1}\right)$ the equilibrium adsorption constant related to the energy of adsorption.

The essential characteristic of the Langmuir isotherm can be expressed in terms of a dimensionless equilibrium factor $R_{\mathrm{L}}$ that is defined as:

$\boldsymbol{R}_{\boldsymbol{L}}=\frac{1}{\left(\mathbf{1}+K_{L} \mathbf{C}_{\mathbf{0}}\right)}$

The adsorption is considered as irreversible when RL $=0$, favourable when $0<\mathrm{R}_{\mathrm{L}}<1$, linear when $\mathrm{R}_{\mathrm{L}}=1$, and unfavorable when RL $>1$.

Freundlich isotherm ${ }^{(24)}$ is an empirical equation assuming heterogeneous adsorptive energies on the adsorbent surface, which can be written

$\operatorname{Ln} q_{e}=\operatorname{Ln} K_{F}+\frac{1}{n} \operatorname{Ln} C_{e}$

Where, $\mathrm{K}_{\mathrm{F}}$ and $\mathrm{n}$ are Freundlich constants related to the adsorption capacity and adsorption intensity, respectively. The value of $0<1 / n<1.0$ exhibits the favourability of adsorption onto activated carbons ${ }^{(25)}$. Temkin isotherm ${ }^{(26)}$ takes into account the adsorbentadsorbate interactions. the heat of adsorption of all the molecules in the layer decreases linearly with coverage due to adsorbent-adsorbate interactions. The adsorption is characterized by a uniform distribution of binding energies, up to some maximum binding energy.
The Temkin isotherm is expressed as:

$\mathrm{q}_{\mathrm{e}}=\mathrm{B}_{\mathrm{T}} \ln \mathrm{K}+\mathrm{B}_{\mathrm{T}} \ln \mathrm{C}_{\mathrm{e}}$

Harkin-Jura isotherm model ${ }^{(27)}$ accounts to multilayer adsorption and can be explained with the existence of a heterogeneous pore distribution. Harkin-Jura model is expressed as follows:

$\frac{1}{q_{e}^{2}}=\frac{B_{2}}{A}-\frac{1}{A} \log C_{e}$

Where A is the Harkins-Jura isotherm parameter, $\mathrm{B}_{2}$ is the Harkins-Jura isotherm constant.

The linear fits of the adsorption equilibrium data at 20 ${ }^{\circ} \mathrm{C}$ of phenols on GAC and RHAC predicted from the four isotherms models were plotted in figure 5 and figure 6 respectively.

The best-fit model was determined by the correlation coefficients $\left(\mathrm{R}^{2}\right)$, the average percentage error APE $(\%)$, and chi test $\left(\mathrm{X}^{2}\right)$. The isotherm parameter values and correlation coefficients $R^{2}$ values, $\mathrm{X}^{2}$ and $\mathrm{APE}(\%)$ are listed in Table 1.

According to the fitting results listed in Table 1, the correlation coefficients of the three models Freundlich, Langmuir, and Temkin, were higher than 0.95. However, when APE (\%) and $\mathrm{X}^{2}$ were considered, the Freundlich isotherm model appeared to be much more applicable than the Langmuir and Tempkin isotherms. The correlation coefficient of Temkin isotherm equation $\left(R^{2}=0.977\right)$ is lower than that obtained for the Freundlich isotherm model $\left(\mathrm{R}^{2}=0.998\right)$ and Langmuir isotherm $\left(\mathrm{R}^{2}=0.984\right)$ for adsorption of phenol on GAC. The correlation coefficient of Freundlich, Langmuir and Temkin isotherm equation for adsorption of phenol on RHAC were $0.992,0.992$, and 0.988 , respectively.

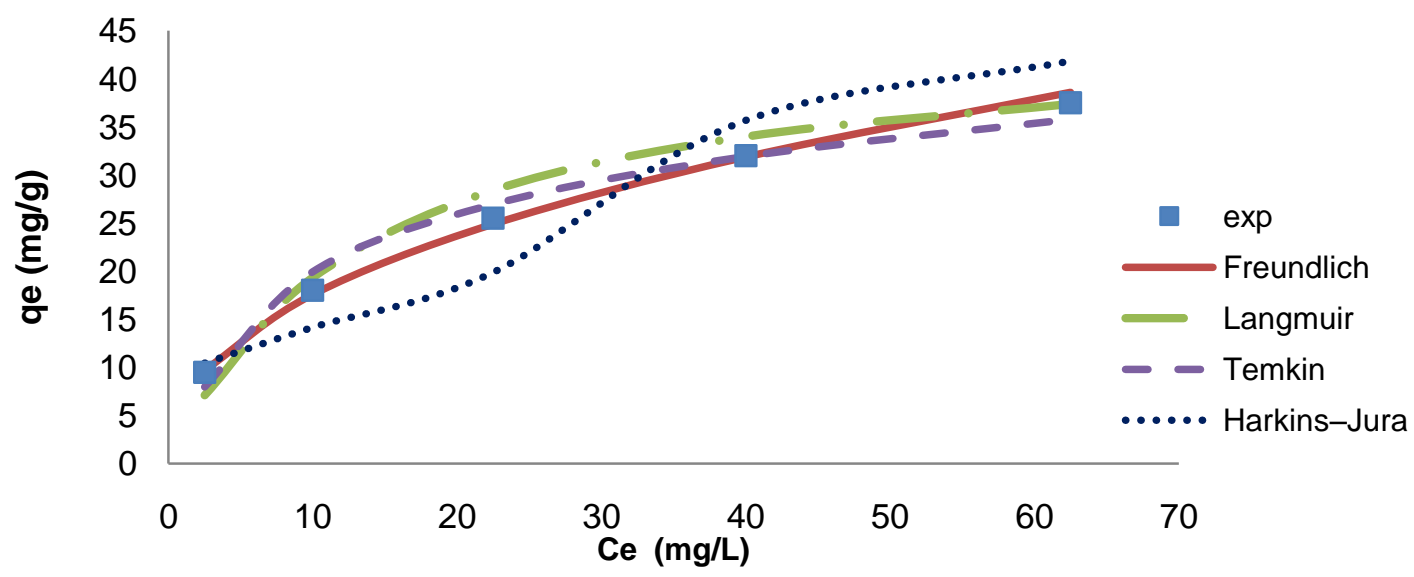

Figure 5: Equilibrium isotherms for the removal of phenol by GAC (Predicted and experimental data of equilibrium adsorption $20^{\circ} \mathrm{C}$ ) 


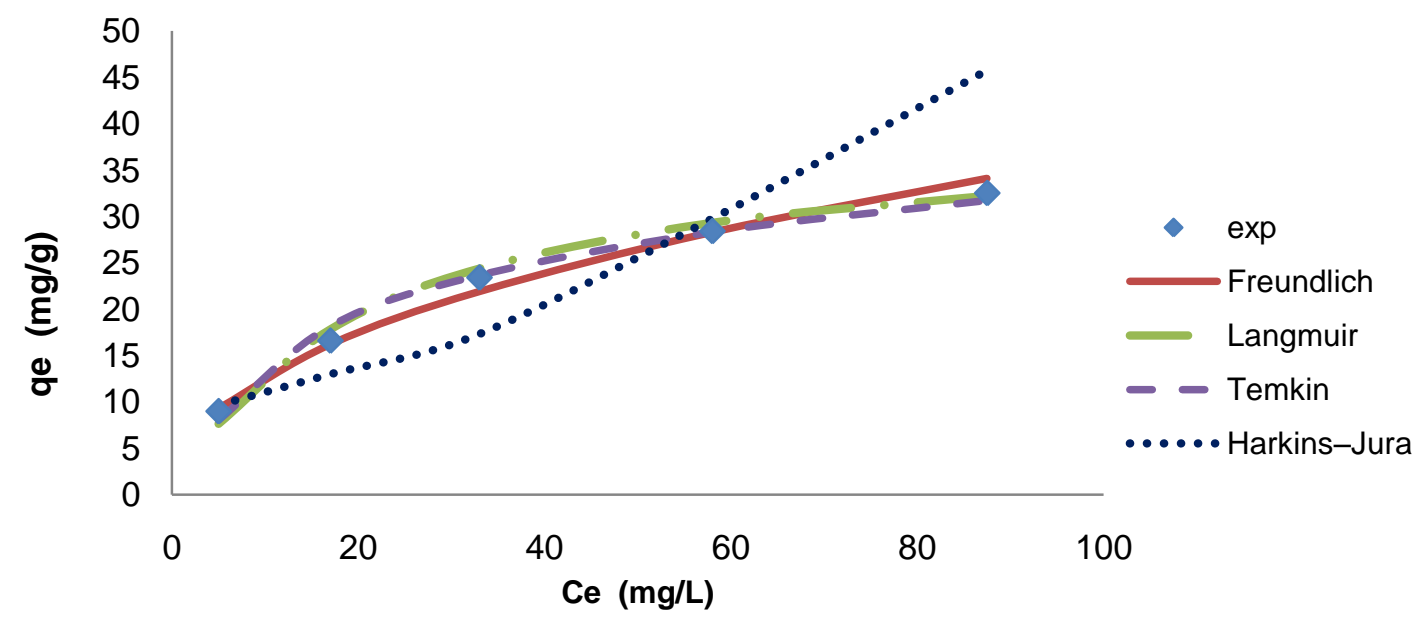

Figure 6: Equilibrium isotherms for the removal of phenol by RHAC (Predicted and experimental data of equilibrium adsorption at $20^{\circ} \mathrm{C}$ )

Table 1: Adsorption isotherm parameters, error analysis values and correlation coefficients calculated for various adsorption models at $20^{\circ} \mathrm{C}$ for phenol on GAC and RHAC

\begin{tabular}{|c|c|c|c|}
\hline \multirow{2}{*}{ Isotherms models } & \multirow{2}{*}{ Isotherms parameter } & \multicolumn{2}{|c|}{ Adsorbents } \\
\hline & & GAC & RHAC \\
\hline \multirow{6}{*}{$\frac{C_{e}}{q_{e}}=\frac{1}{Q_{m} K_{L}}+\frac{1}{Q_{m}} C_{e}$} & $\mathrm{Q}_{\mathrm{m}}(\mathrm{mg} / \mathrm{g})$ & 45.45455 & 40 \\
\hline & $\frac{\mathrm{K}_{\mathrm{L}}}{(\mathrm{mo} / \mathrm{g})(\mathrm{Lg})^{1 / n}}$ & 0.074074 & 0.047259 \\
\hline & $\mathrm{R}_{\mathrm{L}}$ & 0.212598 & 0.297358 \\
\hline & $\mathrm{R}^{2}$ & 0.984 & 0.992 \\
\hline & $\mathrm{X}^{2}$ & 1.316813 & 0.393044 \\
\hline & $\operatorname{APE}(\%)$ & 10.12524 & 4.849892 \\
\hline \multirow{5}{*}{$\begin{array}{l}\text { Freundlich } \\
\qquad \operatorname{Lnq}_{e}=\operatorname{Ln} K_{F}+\frac{1}{n} \operatorname{LnC}_{e}\end{array}$} & $1 / \mathrm{n}$ & 0.429 & 0.454 \\
\hline & $\mathrm{K}_{\mathrm{F}}(\mathrm{L} / \mathrm{mg})$ & 6.548 & 1.44 \\
\hline & $\mathbf{R}^{2}$ & 0.998 & 0.992 \\
\hline & $\mathrm{X}^{2}$ & 0.060107 & 0.197084 \\
\hline & $\operatorname{APE}(\%)$ & 2.025094 & 3.479745 \\
\hline \multirow{4}{*}{ Temkin } & $\mathrm{B}_{\mathrm{T}}(\mathrm{L} / \mathrm{mg})$ & 8.639 & 8.28 \\
\hline & $\mathrm{K}_{\mathrm{t}}(\mathrm{J} / \mathrm{mol})$ & 1.004525 & 0.527496 \\
\hline & $\mathrm{R}^{2}$ & 0.977 & 0.988 \\
\hline & $\mathrm{X}^{2}$ & 0.648514 & 0.273318 \\
\hline \multirow[t]{2}{*}{$q_{e}=B_{T} \ln K+B_{T} \ln C_{e}$} & $\operatorname{APE}(\%)$ & 7.5099 & 4.78394 \\
\hline & A & 142.8571 & 111.1111 \\
\hline \multirow[t]{2}{*}{ Harkins-Jura } & $\mathrm{B}_{2}$ & 1.714286 & 1.888889 \\
\hline & $\mathrm{R}^{2}$ & 0.872 & 0.866 \\
\hline \multirow{2}{*}{$\frac{1}{q_{e}^{2}}=\frac{B_{2}}{A}-\frac{1}{A} \log C_{e}$} & $\mathrm{X}^{2}$ & 3.563224 & 7.07486 \\
\hline & $\operatorname{APE}(\%)$ & 15.2549 & 20.1212 \\
\hline
\end{tabular}

Adsorption Kinetic Models: The adsorption rate data for phenols onto the GAC and RHAC were analysed using two kinetic models pseudo-first-order-equation and pseudo-second-order-equation The pseudo-firstorder model was expressed by Lagergren ${ }^{(28)}$ as :

$\ln \left(q_{e}-q_{t}\right)=\ln q_{e}-k_{1} t$

where $q_{\mathrm{e}}$ and $q_{\mathrm{t}}(\mathrm{mg} / \mathrm{g})$ are the amounts of phenol adsorbed at equilibrium and at any time, $t$ ( $\mathrm{min})$, respectively, and $k_{1}(1 / \mathrm{min})$ is the adsorption rate constant. The plot of $\ln (q \mathrm{e}-q t)$ versus $t$ is shown in figure 7. The values of $k_{1}$, correlation coefficient $R^{2}$, the experimental qe and calculated $q$ cal valued obtained from the linear plots are given in Table 2 . The $R^{2}$ values were 0.953 and 0.969 for phenol of initial concentration of $100 \mathrm{mg} / \mathrm{l}$ onto GAC and RHAC respectively. The experimental qe values 16.6 $\mathrm{mg} / \mathrm{g}$ did not agree with the calculated values $12.3 \mathrm{mg} / \mathrm{g}$ showing that the adsorption of phenol on the RHAC was not a first-order reaction. 


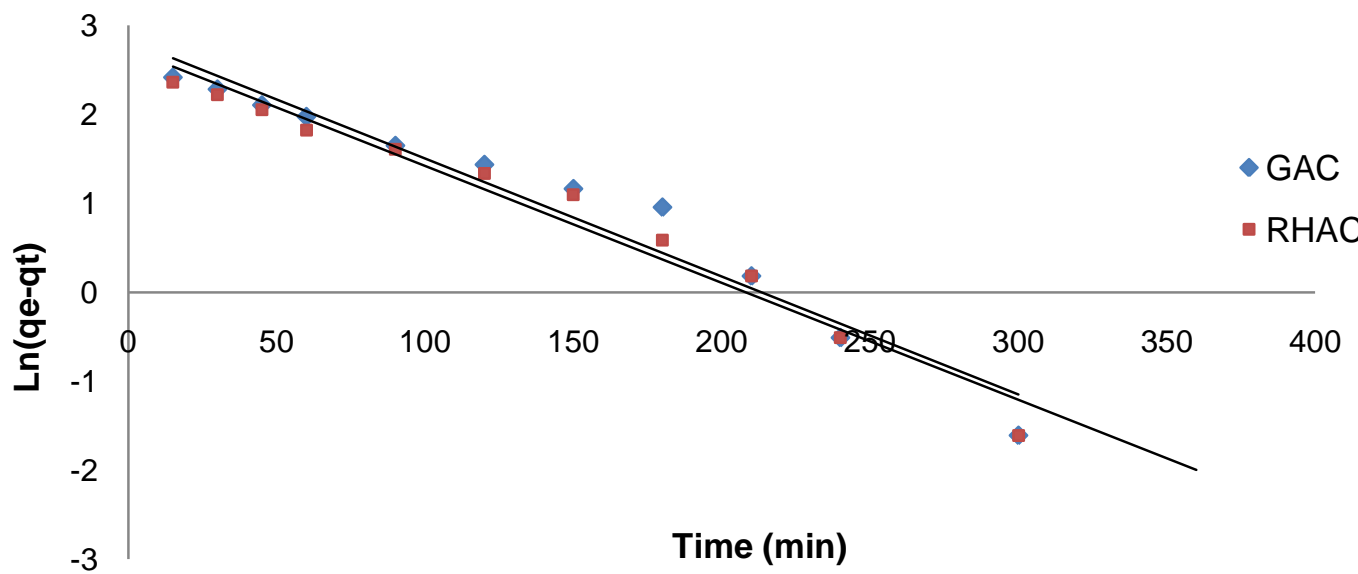

Figure 7: The pseudo-first order model for adsorption of phenol on GAC and RHAC (adsorbent dose 5g/L, initial concentration of phenol $100 \mathrm{mg} / \mathrm{L}$ )

The pseudo-second-order model ${ }^{(29)}$ can be expressed as:

$\frac{t}{q_{t}}=\frac{1}{k_{2} q_{e}^{2}}+\frac{t}{q_{e}}$

where $\mathrm{k}_{2}$ is the second-order rate constant. The values of $\mathrm{t} / \mathrm{qt}$ are plotted against $\mathrm{t}$ as shown in figure $8, \mathrm{q}_{\mathrm{e}}$ and $\mathrm{k}_{2}$ are calculated from the slope and intercept of the plot.
They are listed in Table 2. The pseudo-second-order model fits the experimental data for phenol, the $\mathrm{R}^{2}$ values are $0.992,0.993$ for adsorption of phenol on GAC and RHAC respectively and the experimental and calculated values were found to be in good agreement.

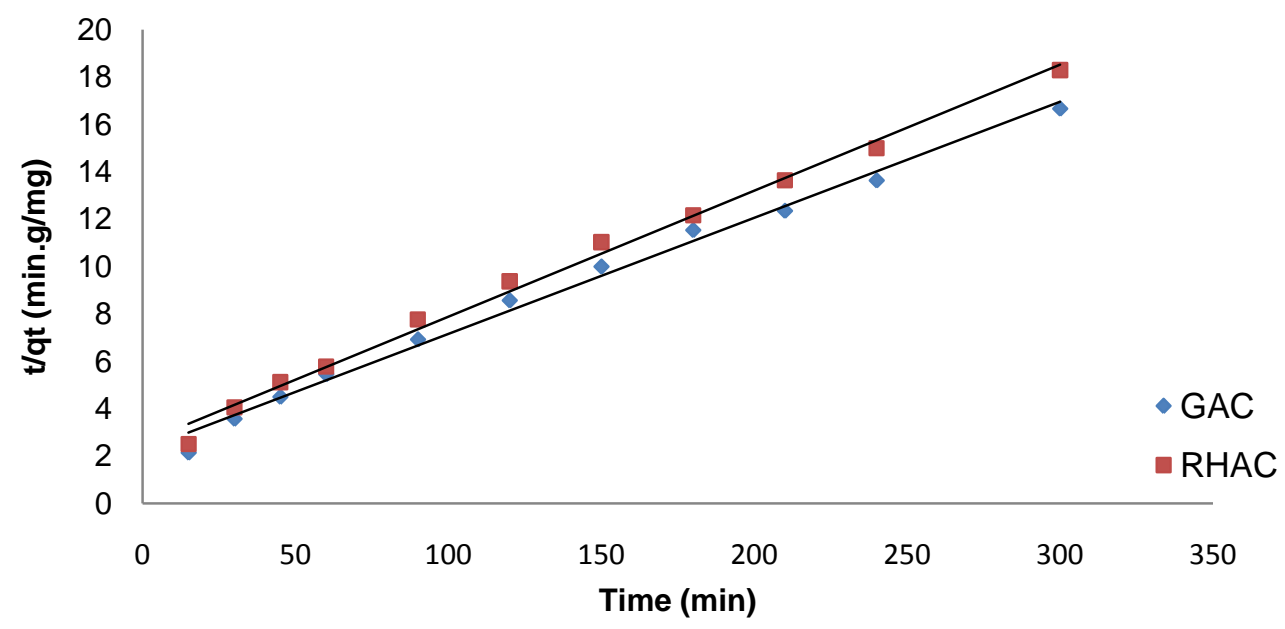

Figure 8: The pseudo-second order model for adsorption of phenol on GAC and RHAC (adsorbent dose 5g/L, initial concentration of phenol $100 \mathrm{mg} / \mathrm{L}$ )

Adsorption Mechanism: The kinetic results were then analyzed by using intraparticle diffusion model to identify the diffusion mechanism and rate controlling steps affecting the kinetics of adsorption. The intraparticle diffusion equation explained by Weber and Morris ${ }^{(30)}$ can be written as:

$q_{t}=k_{\text {diff }} t^{0.5}+C$ where $q$ is the amount of phenol adsorbed $(\mathrm{mg} / \mathrm{g})$ at time $t, k_{\text {diff }}$ is intraparticle diffusion constant $\left(\mathrm{mg} / \mathrm{g} \mathrm{min}{ }^{0.5}\right)$, and $C$ is the intercept which represents the value of the thickness of the boundary layer. Figure 9 illustrates the plots of $q_{t}$ versus $t^{0.5}$. The constants were calculated and listed in Table 2. As can be seen from Figure 9, the linear lines did not pass through the origin and this shows that intraparticle diffusion was not the only rate limiting mechanism in the adsorption process. 


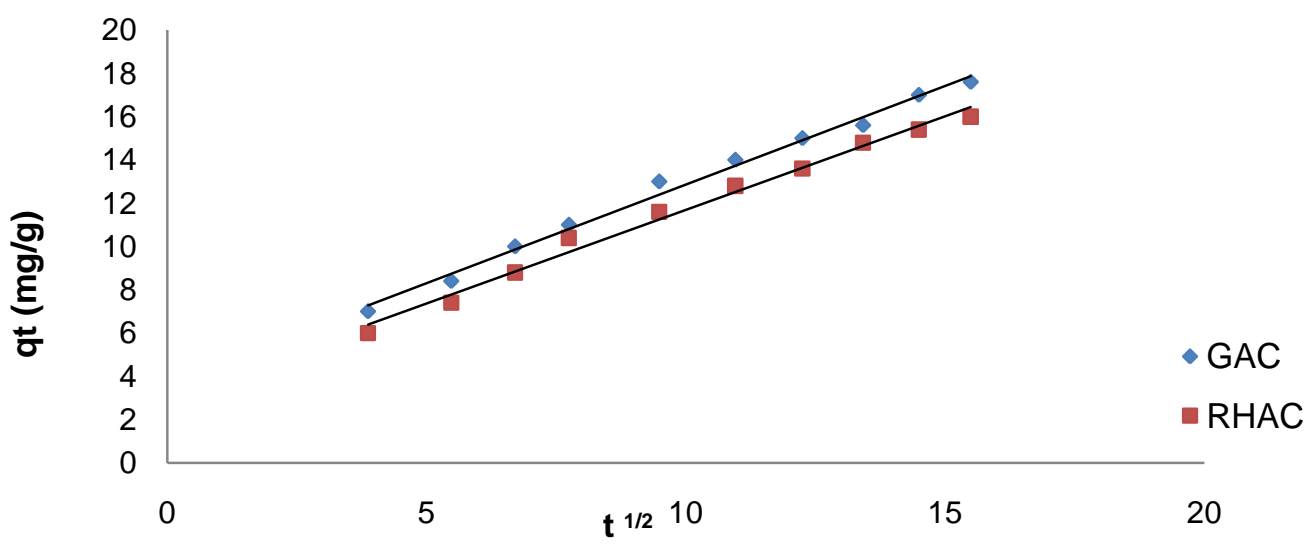

Figure 9: Intraparticle diffusion model for adsorption of phenol on GAC and RHAC (adsorbent dose 5g/L, initial concentration of phenol $100 \mathrm{mg} / \mathrm{L}$ )

Table 2: Pseudo-first-order model, pseudo-second-order model and intraparticle diffusion constants and correlation coefficients for adsorption of phenol on GAC and RHAC at $20^{\circ} \mathrm{C}$

\begin{tabular}{|c|c|c|c|c|c|c|c|c|c|c|}
\hline \multirow[b]{2}{*}{ Adsorbent } & \multirow[b]{2}{*}{$\begin{array}{l}\text { qe } \\
\mathrm{mg} / \mathrm{g}\end{array}$} & \multicolumn{3}{|c|}{ Pseudo-first-order } & \multicolumn{3}{|c|}{ Pseudo-second-order } & \multicolumn{3}{|c|}{ Intra-particle diffusion } \\
\hline & & $\begin{array}{l}q_{\mathrm{mg} / \mathrm{g}} \text { cal } \\
\end{array}$ & $\begin{array}{l}K_{1} \\
1 / \min \end{array}$ & $\mathbf{R}^{2}$ & $\begin{array}{l}\text { q cal } \\
\mathrm{mg} / \mathrm{g}\end{array}$ & $\begin{array}{l}K_{2} \\
10^{-3} \\
\text { g/mg. } \min \end{array}$ & $\mathbf{R}^{2}$ & $\mathbf{C}$ & $\mathbf{K}_{\text {diff }}$ & $\mathbf{R}^{2}$ \\
\hline GAC & 18 & 16.96 & 0.013 & 0.953 & 20.4 & 1.066 & 0.992 & 3.759 & 0.911 & 0.992 \\
\hline RHAC & 16.6 & 12.37 & 0.013 & 0.969 & 18.52 & 1.144 & 0.993 & 3.033 & 0.865 & 0.989 \\
\hline
\end{tabular}

\section{DISCUSSION}

\section{Effect of contact time}

Contact time is an important parameter to determine the equilibrium time of adsorption process. Initially the number of vacant active sites available is higher and the driving force for the mass transfer is greater. Therefore, the adsorbate reaches the adsorption site with ease. As time progresses the number of available free active sites becomes less and the adsorbate molecules are collected at the surface thus impeding the movement of the adsorbate leading to nonlinear adsorption. This can be accounted for the decrease in adsorption rate after $4 \mathrm{hr}$. and was well exhibited by plateau lines at $6 \mathrm{~h}$ of adsorption showing that the process has reached the steady-state condition (figure1).Similar phenomena were previously observed. ${ }^{(31-32)}$

\section{Effect of adsorbent dosage}

The percentage removal of phenol highly increases with the increase in adsorbent dose from $2 \mathrm{~g} / \mathrm{L}$ to $5 \mathrm{~g} / \mathrm{l}$ after which the removal increases slightly (figure 3).These results were in agreement with Kumar S. et al (34) who stated that an increase in the phenol percentage removal with an increase in the adsorbent dosage can be attributed to the increase in the availability of surface area of mesopores for adsorption and, hence, the availability of more adsorption sites.

\section{Effect of initial concentration}

The initial concentration provides an important driving force to overcome all mass transfer resistances of the phenol between the aqueous and solid phases. The percentage removal of phenol was found to decrease with increasing the initial concentrations of phenol in the solution onto both GAC and RHAC (figure4). The higher removal at lower concentrations may be due to the presence of more available sites on the adsorbent. However, at higher concentrations the number of phenol ions in the solution is relatively higher than available sites on the adsorbent for adsorption. ${ }^{(35,36)}$ Previous researchers revealed that the phenol uptake from the solution was related to the mass driving force effect which permits more adsorbates to pass through from the bulk phase boundary to the carbon surface. ${ }^{37}$,

\section{Effect of $\mathrm{pH}$ of the solution}

Phenol was better adsorbed to both adsorbents GAC and RHAC at $\mathrm{pH}$ 6. This behavior can be explained considering the nature of the adsorbent at different $\mathrm{pH}$ .Phenol adsorption can largely be related to the type and ionic state of the functional groups of the adsorbents and also on the phenol chemistry in solution. The decrease in phenol adsorption from $\mathrm{pH} 6$ to 2 was accounted to the increased $\mathrm{H}^{+}$adsorption on 
the carbonyl sites, which suppresses phenol adsorption on these sites. The decrease in the phenol adsorbed from $\mathrm{pH} 6$ to 10.0 on the other hand, was attributed to both greater solubility of dissociated phenol at $\mathrm{pH}>\mathrm{pKa}$ and increased repulsion forces between the dissociated form of the adsorbate and the carbon surface (figure 2). A similar trend of $\mathrm{pH}$ effect was observed for the adsorption of phenol on activated carbon-commercial grade and laboratory grade. ${ }^{(39)}$ The pKa value for phenol is 9.89 , so the adsorbing species above this $\mathrm{pH}$ is mostly anionic. ${ }^{(3)}$ Therefore, the adsorption decrease at high $\mathrm{pH}$ values 10 due to ionization of adsorbate molecules. The reason could be also due to the repulsions between the negative surface charge and the anionic phenolate anions in solution. While, at acidic $\mathrm{pH} 6$ the percentage removal was higher because phenol was undissociated . The low $\mathrm{pH}$ value range $2-5$, additional protons were introduced in the solution and competed for the carbonyl sites, so the adsorption was reduced at low $\mathrm{pH} .{ }^{(10,40)}$

\section{Adsorption Isotherm models}

Adsorption isotherm reveals the relationship between the amount adsorbed by a unit weight of adsorbent and the amount of adsorbate remaining in a solution at a constant temperature under equilibrium condition. It provides the information about the distribution of adsorbable solute between the liquid and solid phases at various equilibrium concentrations. (41) In the present study, four isotherm models have been used in fitting the equilibrium data, namely, Langmuir and Freundlich, Temkin and Hurkin-Jura isotherm models. The results showed that the $\mathrm{n}$ values obtained from the Freundlich model were greater than one representing that the adsorption process onto GAC and RHAC was favourable for phenol. Predicted and experimental isotherms are shown in Figure 5 and 6. It is clear from these figures and from the average percentage error values (Table 1) that there is a good agreement between the experimental and predicted values, suggesting that the Freundlich model is valid for the experimental equilibrium data. Freundlich isotherm is more suitable for the experimental results than the Langmuir, Temkin and Hurkin-Jura because of the lower average percentage error values. These results agree with previous studies on the adsorption of chlorophenols with different adsorbents, where the Freundlich model was fitting the experimental data better than the Langmuir model. ${ }^{(42,43)}$

\section{Adsorption kinetics}

Kinetic study is one of the most important methods to evaluate the efficiency of adsorption. It describes the rate of adsorbate uptake onto adsorbents and the equilibrium time. The present study suggests that the studied adsorption systems follow the secondorder-rate equation instead of the first-order one. Besides, regression coefficients between experimental and calculated values were obtained for the first-order rate model $R^{2}=0.953$ and 0.969 , while second order rate model $R^{2}=0.992$ and 0.993 were also obtained for adsorption of phenol onto GAC and RHAC respectively. Mohan et al., has reported the pseudosecond-order rate equation for the adsorption of pyridine-derivative. $^{(44)} \mathrm{Wu}$ et al., pointed out that the pseudo-second-order model was suitable for the adsorption of lower molecular weight adsorbates on smaller adsorbent particles. ${ }^{(45)}$ Similar observations have previously been reported. ${ }^{(46-48)}$

The adsorption process of the adsorbate molecules from the bulk liquid phase onto the adsorbent surface is presumed to involve three stages: (1) mass transfer of the adsorbate molecules across the external boundary layer; (2) intraparticle diffusion within the pores of the adsorbent; (3) adsorption at a site on the surface. The intraparticle diffusion model proposed by Weber and Morris. ${ }^{(30)}$ If intraparticle diffusion occurs, then $q_{t}$ versus $t^{1 / 2}$ will be linear and if the plot passes through the origin, then the rate limiting process is only due to the intraparticle diffusion. Otherwise, some other mechanism along with intraparticle diffusion is also involved. The intra-particle diffusion model is used to investigate the diffusion controlled adsorption system. The obtained results indicate that intraparticle diffusion was not the only rate limiting mechanism in the adsorption process (figure 9). The existence of an external layer diffusion process could be deduced by the fact that these plots do not pass through the origin ${ }^{(49)}$. Similar results have previously been reported. ${ }^{(50,51)}$

\section{CONCLUSIONS}

Granular activated carbon and activated carbon prepared from rice husk were found to be good adsorbents for the removal of phenol from aqueous solution. The equilibrium time of adsorption is $6 \mathrm{~h}$. The equilibrium data fitted well in the Freundlich model of adsorption. The kinetics of phenol adsorption onto RHAC and GAC followed the pseudo-secondorder model. These results revealed that the rice husk activated carbon could be employed as a low-cost alternative to commercial activated carbon in the removal of phenol from wastewater.

\section{REFERENCES}

1. Lua AC, Jia QP. Adsorption of phenol by oil-palm-shell activated carbons in a fixed bed. Chem. Eng. J. 2009; 150:455-61.

2. Radhika M, Palanivelu K. Adsorptive removal of chlorophenols from aqueous solution by low cost adsorbentkinetics and isotherm analysis. J. Hazard. Mater. 2006; B138:116-24.

3. USEPA, Technical Support Document for Water Quality Based Toxics Control. EPA/440/485032, United States Environmental Protection Agency, Washington, DC, USA, 1985 
4. World Health Organisation (WHO), WHO Guidelines for Drinking Water Quality, World Health Organisation, Geneva, 2004.

5. Kamble SP, Mangrulkar PA, Bansiwal AK, Rayalu SS Adsorption of phenol and o-chlorophenol on surface altered fly ash based molecular sieves .Chem. Eng. J. 2008; 138:7383.

6. Wu Q, Hu X, Yue PL. Kinetics study on catalytic wet air oxidation of phenols. Chem. Eng. Sci. 2003; 58:923-28.

7. Gonz'alez G, Herrera G, Garc'ia MT, Pẽna M, Biodegradation of phenol in a continuous process: comparative study of stirred tank and fluidised-bed bioreactors. Bioresour. Technol. 2001; 76: 245-51.

8. Dabrowski P, Podkoscielny Z, Hubicki M, Barczak. Adsorption of phenolic compounds by activated carbon-a critical review. Chemosphere 2005; 58: 1049-70.

9. Ahmaruzzaman Md. Adsorption of phenolic compounds on low-cost adsorbents: A review. Advances in Colloid and Interface Science. 2008;143: 48-67

10. Liu QS, Zheng T, Wang P, Jiang JP, Nan Li. Adsorption isotherm, kinetic and mechanism studies of some substituted phenols on activated carbon fibers. Chem. Eng. J 2010; 157 :348-56

11. Singh KP, Malik A, Sinha S, Ojha P. Liquid-phase adsorption of phenols using activated carbons derived from agricultural waste material. J. of Hazard. Mater. 2008; 150: 626-41

12. Cao Q, Xie KC, Lu YK, Bao WR. Process effects of activated carbon with large specific surface area from corn cob. Bioresour. Technol. 2006; 97:110-15.

13. Thinakaran N, Baskaralingam P, Pulikesi M, Panneerselvam P, Sivanesan S.Removal of Acid Violet 17 from aqueous solutions by adsorption onto activated carbon prepared from sunflower seed hull, J. Hazard. Mater. 2008;151:316-322

14. Tan IAW, Hameed BH, Ahmad AL.Optimization of preparation conditions for activated carbons from coconut husk using response surface methodology. Chem. Eng. J. 2008; 137:462-470.

15. Miao Q, Tang Y, Xu J, Liu X, Xiao L, Chen Q. Activated carbon prepared from soybean straw for phenol adsorption. J. Taiwan I. . Chem. Eng. 2013; 44 : 458-465

16. Kalderis D , Koutoulakis D, Paraskeva P, Diamadopoulos E, Otal E, Olivares del Valle J, Fern'andez-Pereira C. Adsorption of polluting substances on activated carbons prepared from rice husk and sugarcane bagasse. Chem. Eng. J. 2008;144: 42 50.

17. Guo Y, Zhao J, Zhang H, Qui J, Yang S, Wang Z, Xu H. Use of rice husk based porous carbon for adsorption of rhodamine B from aqueous solutions. Dyes Pigments 2005; 66: 123-128.

18. Rahman IA, Saad B, Shaidan S, Rizal ES. Adsorption characteristics of malachite green on activated carbon derived from rice husks produced by chemical thermal process. Bioresour. Technol. 2005; 96: 1578-83.

19. Akhtar M, Bhanger MI, Iqbal S, Hasany SM. Sorption potential of rice husk for the removal of 2,4-dichlorophenol from aqueous solution: kinetic and thermodynamic investigations. J. Hazard. Mater. 2006; 128: 44-52.

20. Kennedy LJ , Vijaya JJ , Sekaran G , Kayalvizhi K. Equilibrium, kinetic and thermodynamic studies on the adsorption of $m$-cresol onto micro- and mesoporous carbon. J. of Hazard. Mater. 2007; $149: 134-143$

21. Jadhav A J, Srivastava V C. Adsorbed solution theory based modeling of binary adsorption of nitrobenzene, aniline and phenol onto granulated activated carbon. Chem. Eng. J. 2013; 229:450-9.

22. Foo KY, Hameed BH. Insights into the modeling of adsorption isotherm systems. Chem. Eng. J. 2010; 156: 2-10.

23. Langmuir I. The adsorption of gases on plane surfaces of glass, mica and platinum, J. Am. Chem. Soc. 1918; 40:136168.

24. Freundlich HMF. U"ber die adsorption in lo"sungen. Z Phys Chem 1906; 57:385-470.
25. McKay G, Blair HS, Garden JR, Adsorption of dyes on chitin I. Equilibrium studies, J. Appl. Poly. Sci. 1982; 27:3043-57.

26. Tempkin MI, Pyzhev V. Kinetic of ammonia synthesis on promoted iron catalysts. J. Acta Physiochim. URSS 12 (1940) $327-56$.

27. Harkins WD, Jura EJ, The decrease of free surface energy as a basis for the development of equations for adsorption isotherms; and the existence of two condensed phases in films on solids. J. Chem. Phys. 1944; 12:112-13.

28. Ho Y S. Citation review of Lagergren kinetic rate equation on adsorption reactions, Scientometrics .2004; 59: 171-7.

29. G. McKay, Y.S. Ho, Pseudo-second-order model for sorption processes, Process Biochem. 1999;34:451-65.

30. Weber WJ, Morris JC, Kinetics of adsorption on carbon from solution, J. Sanit. Eng. Div. Proceed. Am. Soc. Civil Eng. 1963; 89: 31-59.

31. Bhatnagar A, Removal of bromophenols from water using industrial wastes as low cost adsorbents. J. Hazard. Mater. 2007; 139:93-102.

32. Mall ID, Srivastava VC, Argawal NK. Removal of orange-G and methyl violet dyes by adsorption onto bagasse fly ashkinetic study and equilibrium isotherm analyses. Dyes Pigments. 2006; 69 :210-33.

33. Srivastava VC, Mall ID., Mishra IM, Equilibrium modelling of single and binary adsorption of cadmium and nickel onto baggase fly ash. J. Chem. Eng. 2006;117.

34. Kumar S, Zafar M, Prajapati J K., Kumar S, Kannepalli Sivaram. Modeling studies on simultaneous adsorption of phenol and resorcinol onto granular activated carbon from simulated aqueous solution. J. Hazard. Mater. 2011; 185: 28794.

35. Kilic M, Esin, Apaydin-Varol A, Putun E. Adsorptive removal of phenol from aqueous solutions on activated carbon prepared from tobacco residues: Equilibrium, kinetics and thermodynamics. J. Hazard. Mater. 2011; 189 :397-403.

36. MohdDin A T., Hameed BH., Ahmad A L. Batch adsorption of phenol onto physiochemical-activated coconut shell. J. Hazard. Mater. 2009; $161: 1522-29$.

37. Allen SJ, Gan Q, Matthews R, Johnson PA. Kinetic modelling of the adsorption of basic dyes by kudzu, J. Colloid Interface. Sci. 2005;286: 101-9.

38. Malik PK., Use of activated carbons prepared from sawdusts and rice-husk for adsorption of acid dyes: a case study of acid yellow 36, Dyes Pigments ;2003:56 239-49.

39. Srivastava CV, Mahadeva MS, Indra DM, Basheswar Prasad, IMM. Adsorptive removal of phenol by bagasse fly ash and activated carbon: equilibrium, kinetics and thermodynamics. Colloids Surf. 2006; 272:89-104

40. Moreno-Castilla C. Adsorption of organic molecules from aqueous solutions on carbon materials. Carbon.2004; 42: 8394.

41. Rangabhashiyam S, Anu N, Giri Nandagopal MS, Selvaraju N. Relevance of isotherm models in biosorption of pollutants by agricultural by products. J. Environ. Chem. Eng.2014; 2: 398414.

42. Tan IAW, Ahmad AL, Hameed BH. Adsorption isotherms, kinetics, thermodynamics and desorption studies of 2,4,6trichlorophenol on oil palm empty fruit bunch-based activated carbon, J. Hazard. Mater. 2009; 164: 473-82.

43. Ren L, Zhang J, Li Y, Zhang C. Preparation and evaluation of cattail fiber-based activated carbon for 2,4-dichlorophenol and 2,4,6-trichlorophenol removal. Chem. Eng. J. 2011; 168:55361.

44. Mohan D, Singh KP, Sinha S, Ghosh D. Removal of pyridine derivatives from aqueous solution using low-cost activated carbons derived from agricultural waste material. Carbon.2005; 43:1680-93

45. Wu FC, Tseng RL, Huang SC, Juang RS, Characteristics of pseudo-second order kinetic model for liquid-phase adsorption: a mini-review. Chem. Eng. J. 2009; 151:1-9. 
46. Dursun G, Dursun AY. Adsorption of phenol from aqueous solution by using carbonised beet pulp. J. Hazard. Mater. 2005; $125: 175-82$.

47. Ling R T, Wu KT, Wu FC, Juang RS. Kinetic studies on the adsorption of phenol, 4-chlorophenol, and 2,4-dichlorophenol from water using activated carbons J. Environmental Management .2010; 91: 2208-14.

48. Guocheng L, Jiao H, Liu L, Hongwen M, Qinfang F, Limei W, Mingquan W, Yihe Z. The Adsorption of Phenol by Lignite Activated Carbon Chinese Journal of Chemical Engineering.2011; 19(3):380-5.
49. Mohanty K, Das D, Biswas MN. Adsorption of phenol from aqueous solutions using activated carbons prepared from Tectona grandis sawdust by $\mathrm{ZnCl}_{2}$ activation, Chem. Eng. J. $2005 ; 115: 121-31$.

50. Alhamed Y. Adsorption kinetics and performance of packed bed adsorber for phenol removal using activated carbon from dates' stones J. Hazard. Mater. 2009; 170:763-70.

51. Hameed BH, Rahman AA. Removal of phenol from aqueous solutions by adsorption onto activated carbon prepared from biomass material. J. Hazard. Mater 2008; 160: 576-81. 